\title{
Software designed for fitness club client's requirements management automation
}

\author{
Sergei O. Kurashkin 1, Vladimir V. Bukhtoyarov 1,2, Aleksey N. Bocharov 1,2, \\ Alexander V. Lavrishchev ${ }^{l}$ and Yuriy N. Seregin ${ }^{l}$ \\ ${ }^{1}$ Reshetnev Siberian State University of Science and Technology, 31, Krasnoyarskiy rabochiy pr., Krasnoyarsk, \\ 660037, Russian Federation \\ ${ }^{2}$ Siberian Federal University, 79, Svobodny pr., Krasnoyarsk, 660041, Russian Federation
}

\begin{abstract}
The growth in the amount of information, as well as the expansion of the range of technically complex decision-making problems, require the systematization of existing methods and the development of new methods and algorithms for solving. Artificial neural networks offer promising prospects for development, and software has a huge advantage from their use. In addition, each realizable problem has an unlimited and non-standard set of solution methods. In this paper, we consider the possibility of using a neural network to solve the problem of optimizing data analysis to manage the needs of clients of a fitness club. The main objectives of the research are: an overview of the subject area; identification of deficiencies and setting automation tasks; performing a comparative analysis of existing information systems and performing a comparative analysis of existing software.
\end{abstract}

\section{Keywords}

Neural networks, artificial neural networks, mathematical models, software systems

\section{Introduction}

Each information system (IS) deals with one or another part of the real world, i.e. with a subject area. The study of the subject area is a necessary stage in the development of an automated system. At the stage of studying the subject area, information needs and requests of interested parties, sets of input and output data are determined [1].

In the subject area, to which the task of developing an automated system for recording the achievements of students belongs, the processes of creating, storing, evaluating the information received, as well as issuing the generated output documents from the data warehouse are considered.

The enterprise considered by the authors has a linear management structure that implements the principles of one-man management and centralism. It provides for the performance by one leader of all functions at each level of management, with full subordination to him as one-man command of all subordinate divisions. In turn, he reports to only one superior leader. To solve current problems and prospects for the development of the organization, it would be better to use a linear - functional management structure, which is based on the observance of one-man management, linear construction of structural units and the distribution of management functions between them [2]. The linear functional structure implements the principle of democratic centralism, in which the preparation and discussion of the decision is carried out collectively, and the decision-making and responsibility - only by the first leader alone [3]. It synthesizes the best properties of a linear structure (clear connections of

\footnotetext{
Proceedings of MIP Computing-V 2022: V International Scientific Workshop on Modeling, Information Processing and Computing, January 25, 2022, Krasnoyarsk, Russia

EMAIL: scorpion_ser@mail.ru (Sergei O. Kurashkin); vladber@list.ru (Vladimir V. Bukhtoyarov); sibalexbo@gmail.com (Aleksey N. Bocharov); lav@optilink.pro (Alexander V. Lavrishchev); ius_ceregin@mail.ru (Yuriy N. Seregin)

ORCID: 0000-0002-4017-4369 (Sergei O. Kurashkin); 0000-0003-4505-2851 (Vladimir V. Bukhtoyarov); 0000-0002-8021-0352 (Aleksey N. Bocharov); 0000-0003-4309-8637 (Yuriy N. Seregin)

(c) (i) 2022 Copyright for this paper by its authors.

Use permitted under Creative Commons License Attribution 4.0 International (CC BY 4.0)

CEUR Workshop Proceedings (CEUR-WS.org)
} 
subordination, centralization of management in the same hands) and a functional structure (division of labor, qualified preparation of decisions) [4].

Linear - functional structure is the most common, especially for mid-level management. At the lower levels of management, linear relationships of subordination are more characteristic, and at the upper levels, functional ones [5].

The organizational structure of an organization is understood as the composition, subordination, interaction and distribution of a specific type of work by divisions and management bodies, between which certain relationships are established regarding the implementation of power, command flows and various information. There are several types of organizational structures: linear, functional, linearfunctional, divisional, adaptive [6].

As the organization becomes more complex, it becomes necessary to specialize workers, sections, departments, etc., and a functional management structure is formed. The distribution of work occurs by function [7].

With a functional structure, the organization is divided into elements, each of which has a specific function, tasks. It is typical for organizations with a small nomenclature and stable external conditions. Here there is a vertical: the leader - the functional leaders are the performers [8].

Let us describe the functional responsibilities of several employees of the organization [9].

Administrator - provides work for the effective and cultural service of visitors to the fitness center, creating comfortable conditions for them. Exercises control over the safety of material values. Advises visitors on the availability of available services. Takes measures to prevent and eliminate conflict situations.

Gym instructor - conducting trainings, instructing and advising clients, ensuring the safety of simulators.

Aerobic program instructor - conducting group and individual training in the aerobic room, advising clients on issues of interest.

Director - control of all subordinates, hiring and firing employees, organizing the supply of the necessary equipment.

\section{Material and methods}

In today's world, the systems market has a huge variety of solutions. In this section, we will consider the existing systems, the integration of which is possible in this business process.

Recording your workout results helps you see your progress in exercises, find errors in your program, and discipline yourself. Many people use a regular notebook or notepad for this, but it turned out to be easier and faster to enter data into the phone.

The program can be made each time from a ready-made list of exercises, or you can choose a readymade complex, assembled in advance. This is useful if the set of exercises doesn't change much. If some exercise is not in the list, you can add a new one with a detailed description. Although many other exercise diaries suggest using only your own set of exercises and do not allow you to add new ones.

Most clients do this: they plan a workout in advance according to the set prepared by the complex, fill in the number of approaches and weights. And during training, they simply mark the completed approaches with one click. If you did less or more than planned, you can quickly change the readings.

When you exercise, the app will tell you that in the last workout you took more weight or did more repetitions, and then, perhaps, you should increase the load. There is also a timer and a stopwatch if someone is doing sets on time.

Importantly, GymBoom remembers the results of your workouts and if you think you are doing your best in the gym, the progress chart of your exercises can confirm or deny this. In addition, you can use the "Measurements" section in order to track the dynamics of changes in your body: chest, waist, biceps, etc. All this, combined with motivating quotes from professional athletes, reminds every day why you even started exercising.

Let's take a look at the GymBoom system first. This system is a calendar with a catalog of exercises. Everything works simply: select the date, time and training program, indicate the number of approaches and weight for each exercise. The system interface is shown in Figure 1. 


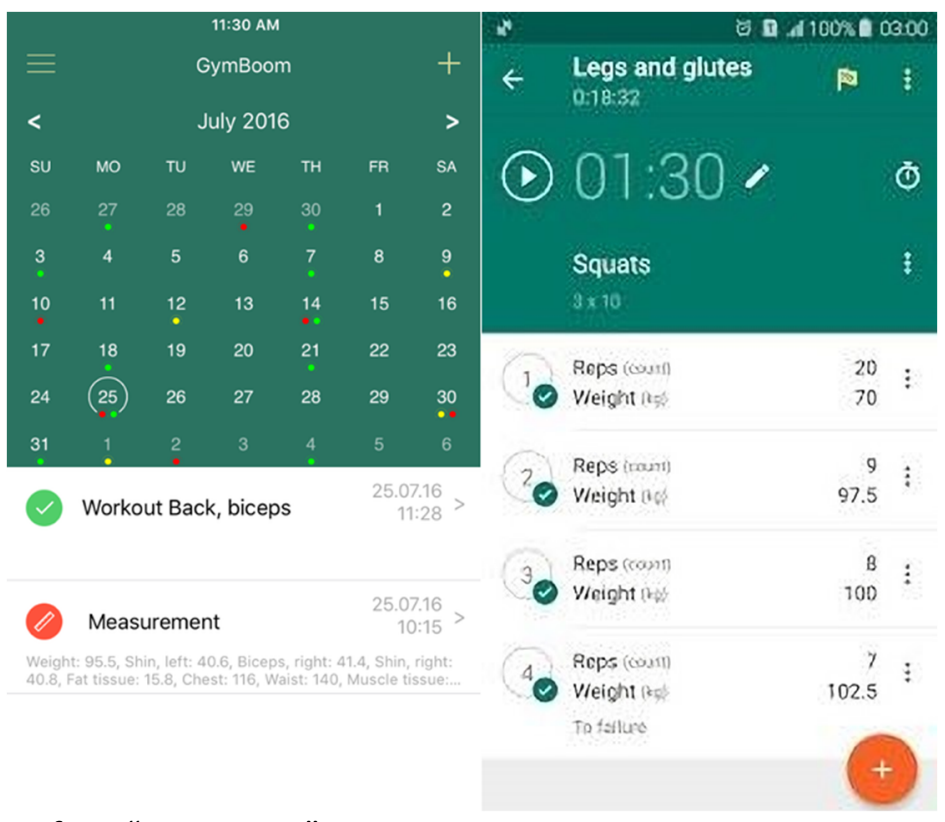

Figure 1: Program interface "GymBoom"

There is also paid functionality in the application: training programs, divided depending on the goal, gender and age of the user, his level of training and body type. For the absence of ads in the application and a fully functional Calendar (in the free version, you can plan workouts only for a month), you will also have to pay for the Pro version using donations.

The second system we will consider is "GymApp". Workout diary "GymApp Pro" for Android is not quite an ordinary application for the operating system from Google from a newcomer to the mobile market, but with big ambitions and a good reputation, adhocapp. Before installation, we advise you to pay attention to the amount of available memory in the device [10].

The required version is Android 3.2 or later, so please check which operating system you have, due to a mismatch, you will not be able to run the application after installation. We draw your attention to the fact that the GymApp Pro workout diary application is among the leaders in its category, and the number of all installations, according to the statistics of the most popular mobile application portal, is 5,000-10,000, maybe this does not impress you, but deserves attention [eleven]. The system interface is shown in Figure 2.

Figure 2: Program interface "GymApp"

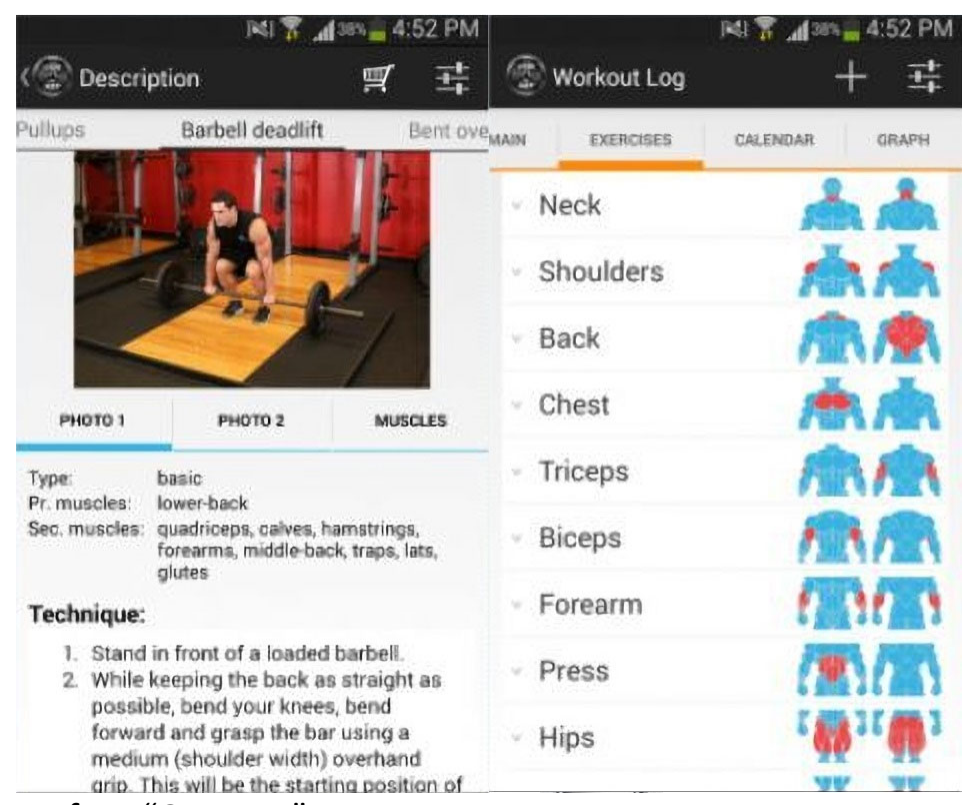


The first thing that you can pay attention to and that all users will surely like is simple and at the same time interesting graphics, and together with a well-done task management process and correctly selected sound of the main actions, we get a noteworthy software product. The current version at the time of writing is 1.8.15, in which the developer has removed all known flaws and errors.

This free application has a wide range of functions that will be indispensable both inside the hall and outside. Make your own plan for developing your body using a variety of techniques and methods.

System functionality. The application for android has many built-in useful features that may become indispensable in the daily life of any athlete.

You can also go to YouTube to watch the technique, but before that you have to watch the ad several times.

During a workout to add a set, a new window opens each time, the weight and reps are saved from the previous set.

Another system is iGym Pro [12]. This is a complete electronic trainer. The lesson diary allows you to monitor progress, make schedules. The program interface is shown in Figure 3. Paid programs for achieving specific goals. Graphs and charts that display training statistics allow you to track your results. A wide selection of ready-made training programs. If you wish, you can create your own, taking into account the result that you want to get. The timer will allow you to control the time allotted for training and enter the data for each approach in an individual log. A huge selection of exercises for working out different muscle groups with a description of the execution technique and illustrations. Ability to schedule classes for the week.

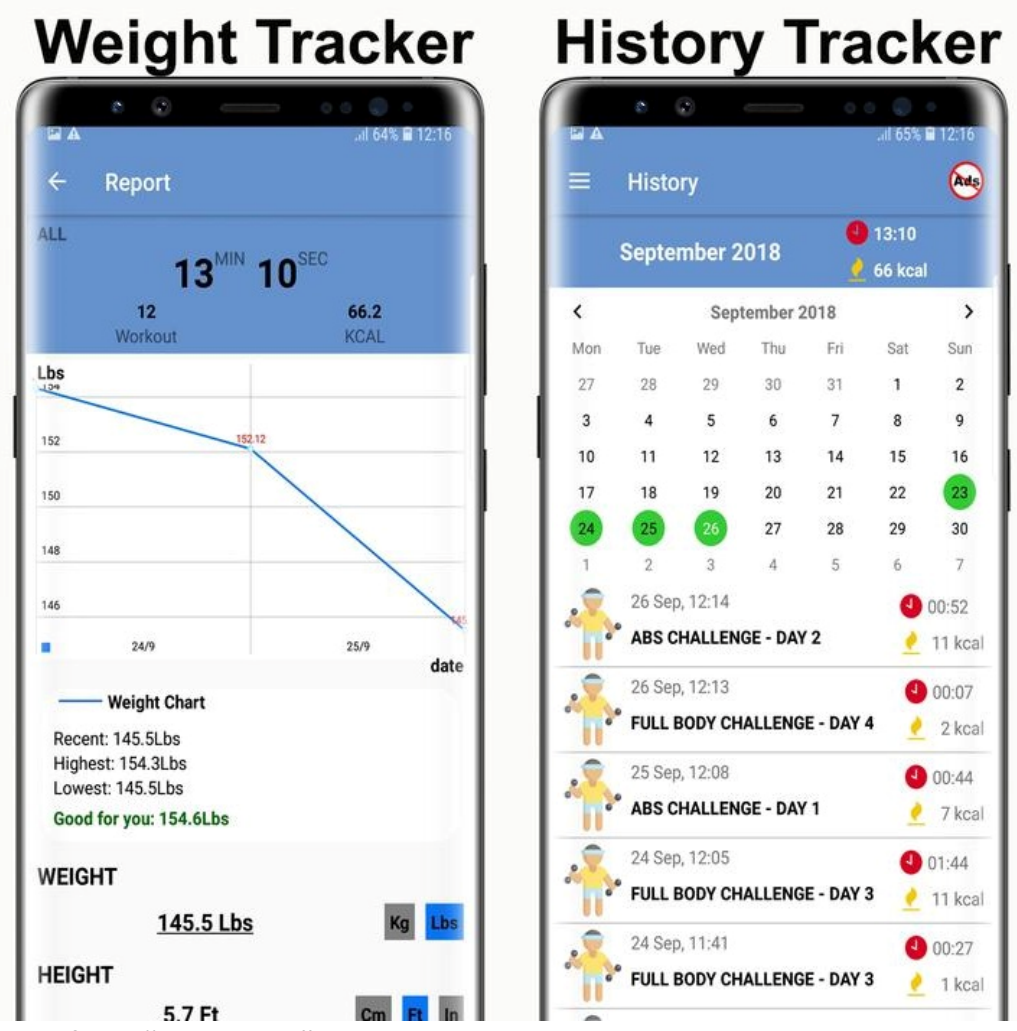

Figure 3: Program interface "iGym Pro"

Also the leading system is "Daily Strength" [13], the interface of which is shown in Figure 4. The application is ideal for beginners. Will help you master basic bodybuilding techniques. Self-training with this application will allow you to get a lean and strong body. Each program lists the number of approaches, repetitions and days of the week when it is performed. Exercises for working out the whole body in the form of a list, where they are arranged alphabetically, which greatly facilitates the search. A detailed description of the exercise technique, animation and video format, allow you to avoid mistakes. Timer, accounting of results. For advanced athletes, paid programs are offered. 


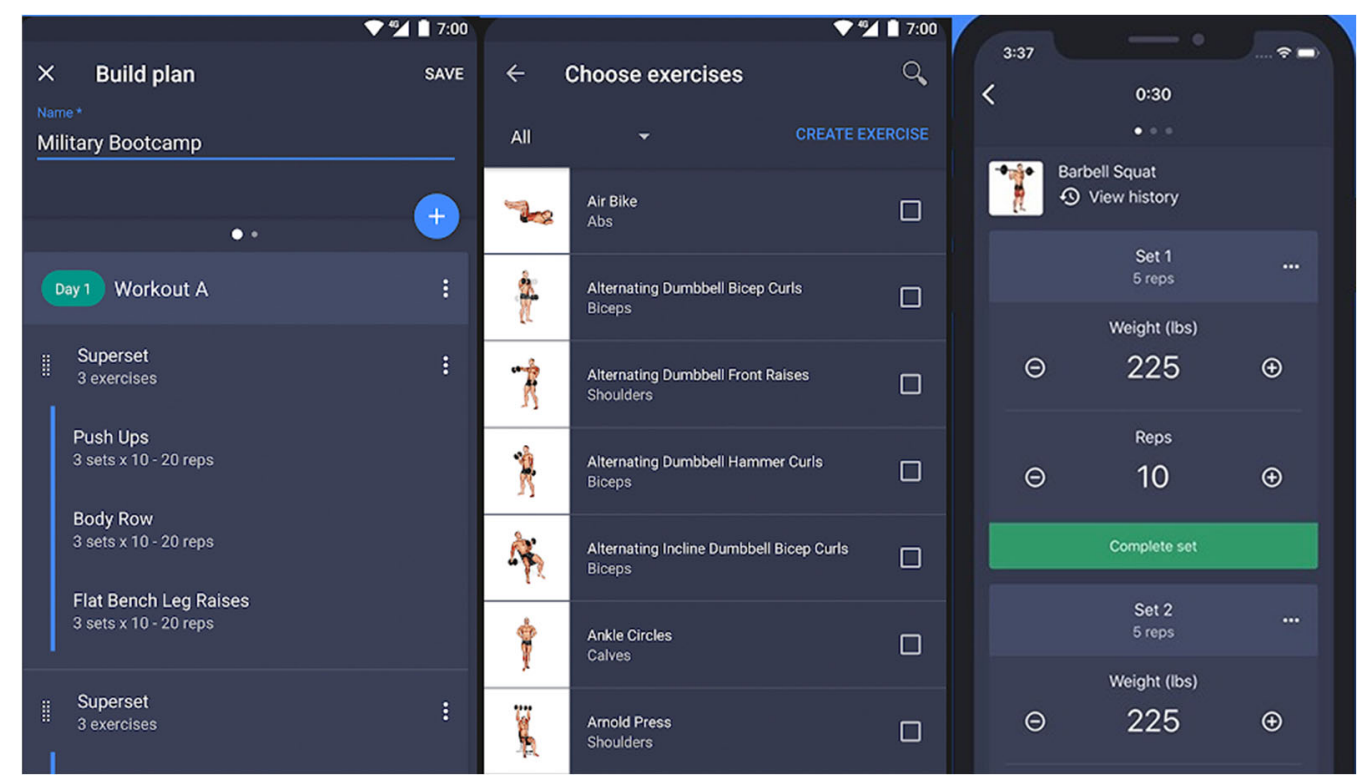

Figure 4: Program interface "Daily Strength"

When self-training in the gym, the electronic assistant will record the approaches, compile statistics, and also advise exercises, depending on the goals that the person sets for himself. Special mobile applications will successfully cope with the task and will greatly facilitate the control over the training process. Table 1 shows a comparison of the above systems in terms of the main parameters.

\section{Table 1}

Stub manufacturing technology

\begin{tabular}{cccccc}
\hline & $\begin{array}{c}\text { Monitoring } \\
\text { health } \\
\text { indicators }\end{array}$ & $\begin{array}{c}\text { Collection of } \\
\text { personal } \\
\text { training }\end{array}$ & $\begin{array}{c}\text { Calculation } \\
\text { of KBZHU }\end{array}$ & $\begin{array}{c}\text { Selection of } \\
\text { personal } \\
\text { directions of } \\
\text { group programs }\end{array}$ & $\begin{array}{c}\text { Advertising } \\
\text { and paid } \\
\text { services in } \\
\text { the system }\end{array}$ \\
\hline GymBoom & + & + & + & - & + \\
GymApp Pro & + & - & - & - & + \\
iGym Pro & - & - & + & - & + \\
Daily Strength & + & + & - & & + \\
\hline
\end{tabular}

Based on the comparative analysis, it can be concluded that the existing systems do not meet the needs of the organization's customers. Thus, the task of creating an intelligent data analysis system to manage customer needs becomes urgent.

\section{Result and discussion}

The intelligent system is designed to accumulate data on the health status of clients, create a system for monitoring and assessing the body of each client of a fitness center, tracking their dynamics and forecasting by receiving summary charts and reports for a certain time period.

Let's consider the options for using this system in a fitness center. The use case diagram demonstrates the relationship between actors and use cases, thus describing the logical model of the IS being developed. Figure 5 shows how an entity interacts with the system.

Authorization is a dialog box with input fields "Login" and "Password". For each user group, access rights to certain software modules are defined.

The program supports the input of reference information for storage in the database: to keep track of strategies, tasks and task items in the information system, the user is provided with the "Maintain database" function with the ability to add, change or delete these objects. 
The "Manager" user can create and / or edit reports, as well as track their progress using the corresponding functions of the system.

The function "Calculate KBZHU" for the user "Consumer" allows you to calculate data using a special formula for a specific Consumer.

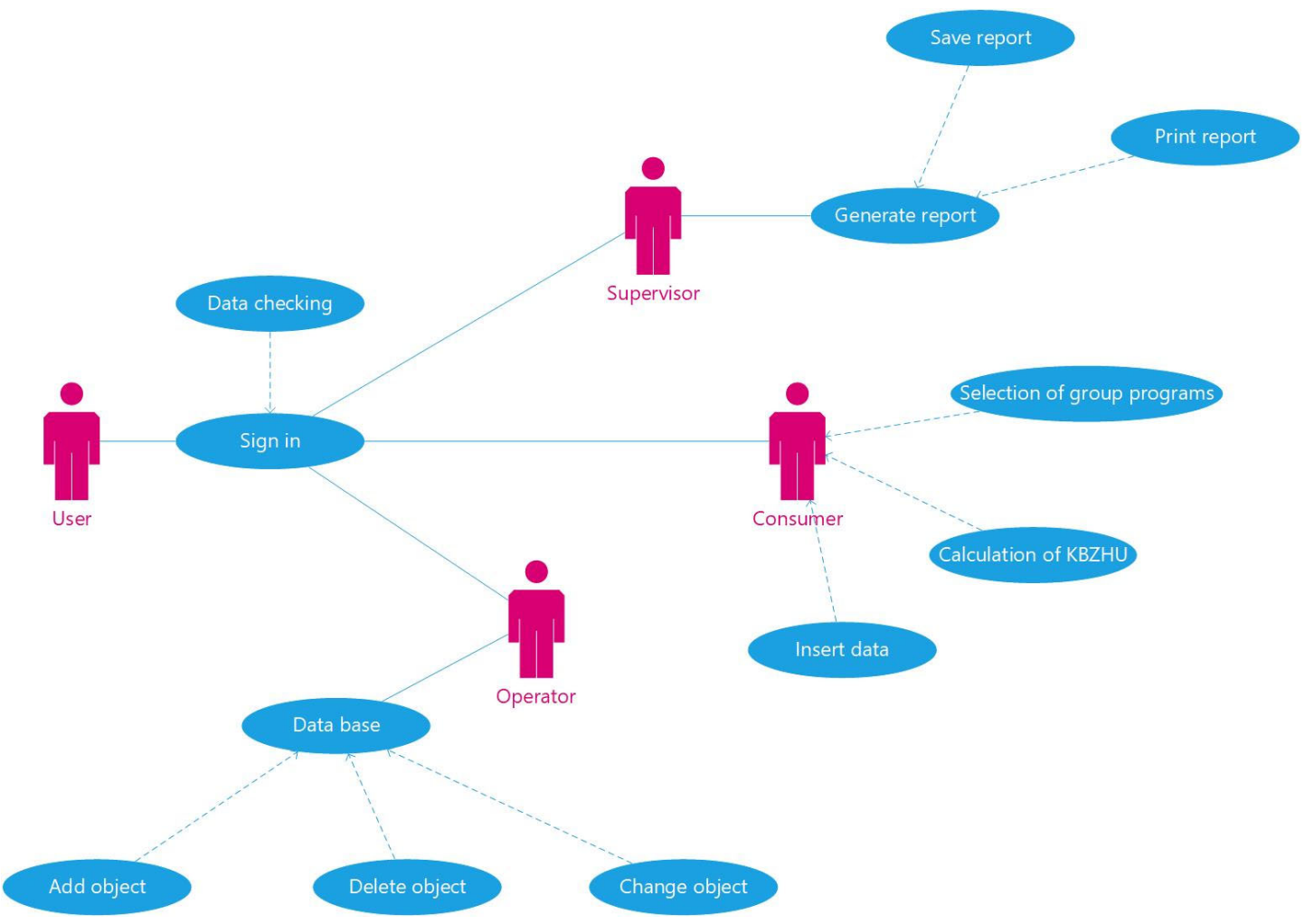

Figure 5: Use Case Diagram

The "Generate Report" function allows you to view and print reports generated according to various criteria.

Also consider the class diagram and the cooperation diagram. A class diagram is a form of static description of a system in terms of its design, showing its structure. It allows you to define the relationship between classes and their instances to model the application area.

The class diagram consists of the following system elements: User, Personal computer, Database, Computer keyboard, Printer, Computer screen, Application (for working with databases and forms), as well as the "Report" form.

Classes contain attributes that reflect basic information about what a particular class is. In addition to attributes, classes contain methods that allow you to perform any specific specified actions. The classes are connected with each other by directional association with cardinality at the ends. Classes can be connected by association of the "aggregation" type. This means that one class includes another class as a constituent part, and the destruction of any object of the class should not lead to the destruction of the objects of another class associated with it.

A collaboration diagram shows how objects interact when implementing specific use cases. It describes the static structure and dynamic behavior of the system.

At the first step, the user enters a username and password for authorization in the system (link 1). After that, the data is checked for correctness (link 2). After successfully entering the login and password, screen forms (link 3) are displayed on the monitor and data from the database is loaded (link 4). Further, the user sets the criteria for generating the report he needs (link 5), and the personal computer sends a request to the database to filter the data according to the specified parameters (link 6). After that, the presented report (link 7) is displayed on the monitor. At the last step, the generated report is sent to print (link 8).

During the physical design of a database in MySQL 5.6, table designs are drawn up, which will be further implemented in a specific database. The physical layout of the database is shown in Figure 6. 


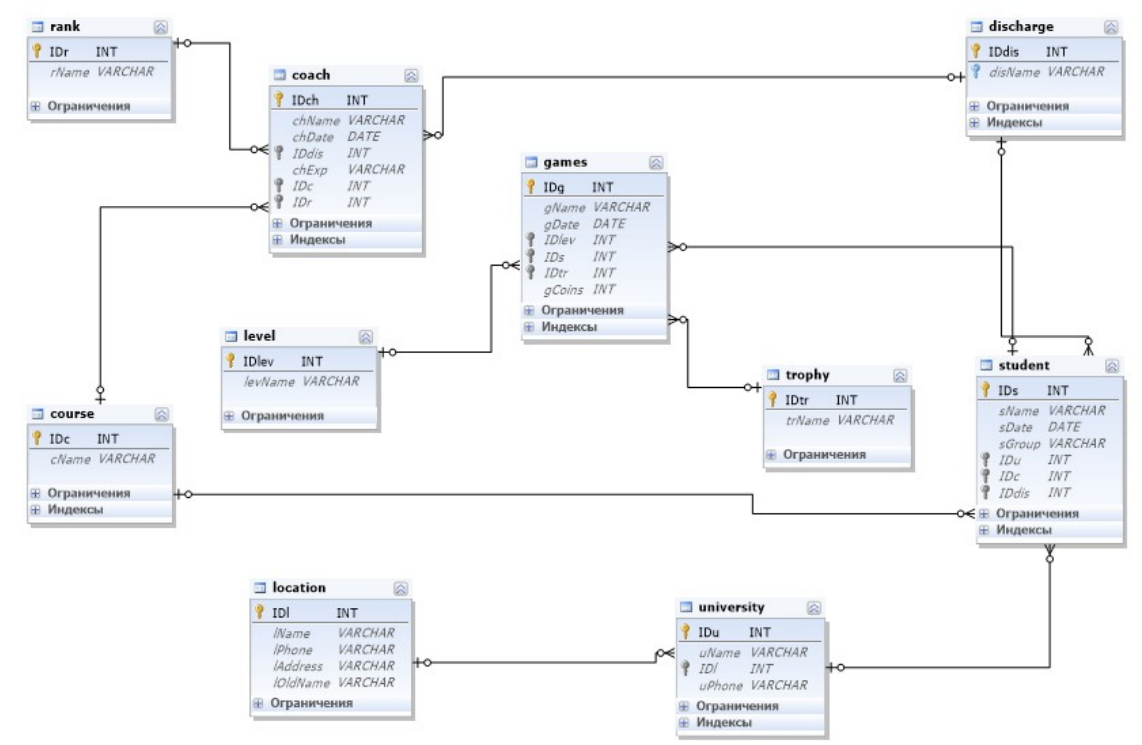

Figure 6: Physical data schema

\section{Conclusion}

As a result of the work, the authors conducted a review of the subject area, during which the shortcomings of existing systems were identified, and the authors formulated the setting of automation problems. In addition, the authors performed a comparative analysis of existing software and existing information systems, as a result of which four well-known systems (GymBoom, GymApp Pro, iGym Pro, Daily Strength) were studied, and a table with criteria was compiled. Comparative analysis showed the absence of direct analogues of the developed system, since each organization forms its own needs of clients. Foreign ICs are inaccessible to most fitness centers due to the high cost per use, and Russian systems allow only limited analysis of activities. Most of these systems either do not at all allow the creation of reporting documentation and comparative charts based on the results of the analysis of activities, or the display of charts and reports is simplified as much as possible and does not imply the solution of serious problems.

For the direct implementation of the database, MySQL 5.6 was chosen as the most consistent with the presented criteria necessary for the implementation of the final qualifying work. On the basis of the research, a database of baths was designed, which will form the basis of the future software product for a fitness club.

\section{References}

[1] C. S. Chapman, L. A. Kihn, Information system integration, enabling control and performance, Accounting, Organ. Soc. 34 (2009) 151-169.

[2] A. Cuevas, M. Febrero, R. Fraiman, Linear functional regression: The case of fixed design and functional response, Can. J. Stat. 30 (2002) 285-300.

[3] M. V. Lysanova, V. D. Sukhov, Linear-Functional Schemes to Manage Construction in Modern Conditions, Components Sci. Technol. Prog. 1 (2017) 21-23.

[4] A. Inoue, M. A. Deng, design of a partial sliding mode controller using duality to linear functional observer, IEEE International Symposium on Intelligent Control 10 (2009) 488-491.

[5] Y. Wang, L. Liu, S. Guo, Q. Yue, P. Guo, A bi-level multi-objective linear fractional programming for water consumption structure optimization based on water shortage risk, J. Clean. Prod. 237 (2019) 117829.

[6] G. A. Ahmady, M. Mehrpour, A. Nikooravesh, Organizational Structure, Procedia - Soc. Behav. Sci. 230 (2016) 455-462. 
[7] F. C. Lunenburg, Organizational Structure: Mintzberg's Framework, Int. J. Sch. Acad. Intellect. Divers. 14 (2012) 1-8.

[8] C. Homburg, J. P. Workman, O. Jensen, Fundamental changes in marketing organization: The movement toward a customer-focused organizational structure, J. Acad. Mark. Sci. 28 (2000) 459478.

[9] Levchuk G M, Levchuk Y N, Luo J, Pattipati K R and Kleinman D L Normative design of organizations - Part II: Organizational structure, IEEE Trans. Syst. Man, Cybern. Part ASystems Humans 32 (2002) 360-375.

[10] P. Viana, T. Ferreira, L. Castro, M. Soares, J. P. Pinto, T. Andrade, P. Carvalho, GymApp: A real time physical activity trainner on wearable devices, in: Proc. - 2018 11th Int. Conf. Hum. Syst. Interact. (HIS), Gdansk, Poland, 2018, pp 513-518.

[11] A. González Ortega, and V. F. López, GymApp, E. T. en Informàtica Gestió 12 (2015) 1-10.

[12] R. Graf, P. Benawri, A. E. Whitesall, D. Carichner, Z. Li, M. Nebeling, H. S. Kim, Igym: An interactive floor projection system for inclusive exergame environments, in: Proc. Annu. Symp. Comput. Interact. Play, Barcelona, Spain, 2019, pp 31-43.

[13] E. V. Tararushkin, T. N. Shchelokova, Daily strength testing of the Portland cement mortars, IOP Conf. Ser. Mater. Sci. Eng. 862 (2020) 022031. 